\title{
Flexural Behavior of High-Volume Steel Fiber Cementitious Composite Externally Reinforced with Basalt FRP Sheet
}

\author{
Seungwon Kim and Cheolwoo Park \\ Department of Civil Engineering, Kangwon National University, 346 Choongang-ro, Samcheok 25913, Republic of Korea \\ Correspondence should be addressed to Cheolwoo Park; tigerpark@kangwon.ac.kr
}

Received 23 September 2016; Accepted 20 November 2016

Academic Editor: Peng Zhang

Copyright (C) 2016 S. Kim and C. Park. This is an open access article distributed under the Creative Commons Attribution License, which permits unrestricted use, distribution, and reproduction in any medium, provided the original work is properly cited.

\begin{abstract}
High-performance fiber-reinforced cementitious composites (HPFRCCs) are characterized by unique tensile strain hardening and multiple microcracking behaviors. The HPFRCC, which demonstrates remarkable properties such as strength, ductility, toughness, durability, stiffness, and thermal resistance, is a class of fiber cement composite with fine aggregates. It can withstand tensile stresses by forming distributed microcracks owing to the embedded fibers in the concrete, which improve the energy absorption capacity and apparent ductility. This high energy absorbing capacity can be enhanced further by an external stiff fiber-reinforced polymer (FRP). Basalt fabric is externally bonded as a sheet on concrete materials to enhance the durability and resistance to fire and other environmental attacks. This study investigates the flexural performance of an HPFRCC that is externally reinforced with multiple layers of basalt FRP. The HPFRCC considered in the study contains steel fibers at a volume fraction of $8 \%$.
\end{abstract}

\section{Introduction}

The high-performance fiber-reinforced cementitious composite (HPFRCC) is a class of fiber cement composite with fine aggregates that exhibits remarkable properties such as strength, ductility, toughness, durability, stiffness, and thermal resistance. It can withstand tensile stresses by forming distributed microcracks owing to the embedded fibers in the concrete, which improve the energy absorption capacity and apparent ductility [1]. Fiber-reinforced polymer (FRP) composites are attractive and advantageous lightweight materials used for the rehabilitation and retrofitting of reinforced concrete and prestressed concrete structures. In the past few decades, the externally bonded FRP has evolved into an advanced and well-established technology. Lightweight FRP strips are easy to handle and can be installed without heavy equipment. This study investigates the flexural performance of an HPFRCC that is externally reinforced with multiple layers of basalt FRP with different strip orientations.

Currently, the service life extension of structures is an important concern that must be addressed. The choice of the strengthening systems directly depends on the performance, which is based on requirements such as increasing flexural, shear, torsion strength, or ductility of the structures. In addition to ongoing construction works of civil engineering infrastructure, existing structures should be considered as well. The complete replacement of structures is not an option owing to the financial burden and effort involved during construction in the past.

Terrorist attacks are one of the most pressing issues confronting the world today [2], and civil engineering structures are the most vulnerable to the destructive effects of such attack. For this reason, there has been an increased interest in developing materials with high toughness that resist impacts and blast loading. Recently, there have been a number of explosion accidents involving structures of nuclear facilities and refinery plant facilities, which resulted in very severe damage to human lives and properties. This type of unexpected loading in the form of blast or impact may cause serious fire accidents as well. In order to prevent or reduce the damage from such unexpected loadings, innovation in the cement concrete technology is considered to be one of the most practical engineering solutions.

The HPFRCC is a recent development that can provide a possible solution for localized severe wide cracks [3] because of its unique ability to induce a number of finely 


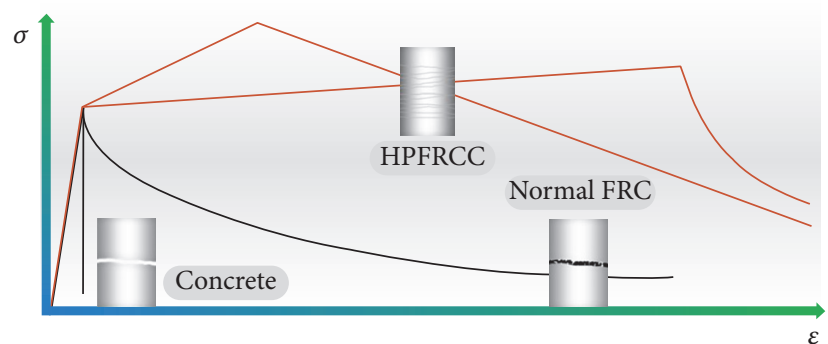

FIgURE 1: Pseudo-strain hardening behavior of HPFRCC.

distributed cracks. The other characteristics of HPFRCCs include the crack width controlling capability by keeping the width within a permissible range. In addition, an appropriate use of its tensile performance can result in a structural component that is excellent in both durability and mechanical performance. Such materials are suitable in defense shelter blast proofing and retrofitting schemes and in structures that are routinely subjected to energy-intensive dynamic incidents [4]. The HPFRCC functions as the most effective alternative to all other previous materials that were being used to resist high impact energy. Figure 1 shows the pseudo-strain hardening behavior of HPFRCC in comparison with normal concrete and normal fiber reinforced concrete.

Further strengthening this high-performance concrete material would be a good move to make it a perfect structure that can resist various damaging factors. For this purpose, FRP can be applied to the HPFRCC as protection against the external environment, fiber corrosion, and so forth. Moreover, the FRP can provide a greater durability and resistance to the HPFRCC because of the externally bonded reinforcement [5].

Epoxy adhesives are used to bond FRPs to HPFRCCs. The viscosity of epoxy adhesive is sufficient to hold the self-weight of the polymer. Furthermore, highly advanced manufacturing technologies can produce polymers with accurate alignment and minimum voids. However, there is a drawback-the reduction in ductility of the strengthened member. This loss in ductility has led to the formulation of various design guidelines for the external strengthening of FRP composites [6, 7].

The service life of a concrete structure is often shorter than planned. This is mainly due to environmental interactions that may occur. Because of its high strength and superior resistance against environmental agents, the use of the advanced basalt fiber-reinforced polymer (BFRP) as a structural reinforcement is a promising alternative, particularly as an externally bonded reinforcement for concrete structures [8]. Strengthening of concrete structures using the BFRP external reinforcement is an interesting topic, because studies of flexural strengthening with cement-based material as a bonding agent are relatively new, and therefore, it is important to investigate the suitability of such a material as a bonding agent. To achieve this, a full-scale test will be performed to demonstrate the actual behavior of the retrofitted structure in order to gain a better understanding of the performance of the system as a whole.
TABLE 1: Chemical composition and physical properties of cement and silica fume.

\begin{tabular}{lcc}
\hline Chemical composition (\%) & Cement & Silica fume \\
\hline $\mathrm{CaO}$ & 60.12 & 0.38 \\
$\mathrm{Al}_{2} \mathrm{O}_{3}$ & 6.59 & 0.25 \\
$\mathrm{SiO}_{2}$ & 21.95 & 96.00 \\
$\mathrm{Fe}_{2} \mathrm{O}_{3}$ & 2.81 & 0.12 \\
$\mathrm{MgO}$ & 3.32 & 0.10 \\
$\mathrm{SO}_{3}$ & 2.11 & - \\
Particle size $\left(\mathrm{cm}^{2} / \mathrm{g}\right)$ & 3,400 & 200,000 \\
Specific gravity & 3.15 & 2.10 \\
\hline
\end{tabular}

\section{Material Properties and Experimental Method}

\subsection{Materials}

2.1.1. Ordinary Portland Cement. Ordinary Portland cement used in this experiment is one of the most widely used construction materials in civil engineering projects worldwide. This type of cement is made from calcareous materials such as limestone or chalk and from alumina and silica obtained as clay or shale. The major constituents of this cement are categorized into four compounds as shown in Table 1.

2.1.2. Silica Fume. Silica fume with the composition shown in Table 1 is an enhancer that substantially improves the mechanical properties. It is an extremely fine powder, with particles approximately 100 times smaller than cement. The particles of such a material pack tightly against the surface of the aggregate and fit in between the cement particles, greatly improving the packing [9].

2.1.3. Steel Fiber. The quantity of steel fibers required for a concrete mix is normally determined as a percentage of the total volume of the composite materials. The fibers are bonded to the material to produce a fiber-reinforced concrete that can withstand considerable stresses during the postcracking stage. The actual effect of the fibers is to increase the concrete toughness. The hooked end steel fiber used in this study which is shown in Figure 2 has a density of $7.8 \mathrm{~g} / \mathrm{cm}^{3}$, length of $30 \mathrm{~mm}$, diameter of $0.5 \mathrm{~mm}$, aspect ratio of 60 , and tensile strength of 1,200 $\mathrm{MPa}$. It is used to improve the fracture toughness under the application of tensile and bending stresses.

2.1.4. Superplasticizer. To improve the workability of the concrete, a superplasticizer was added during the mixing operations. Superplasticizers, also known as high-range water reducers, are chemical admixtures used where well-dispersed particle suspension is required.

2.1.5. Adhesive. Strong adhesives are available for FRP plate bonding, and their strength generally exceeds that of the concrete. Therefore, failure in the adhesive is rare. However, if substandard adhesives are used or if adhesives are not properly applied, the failure may occur within the adhesive 

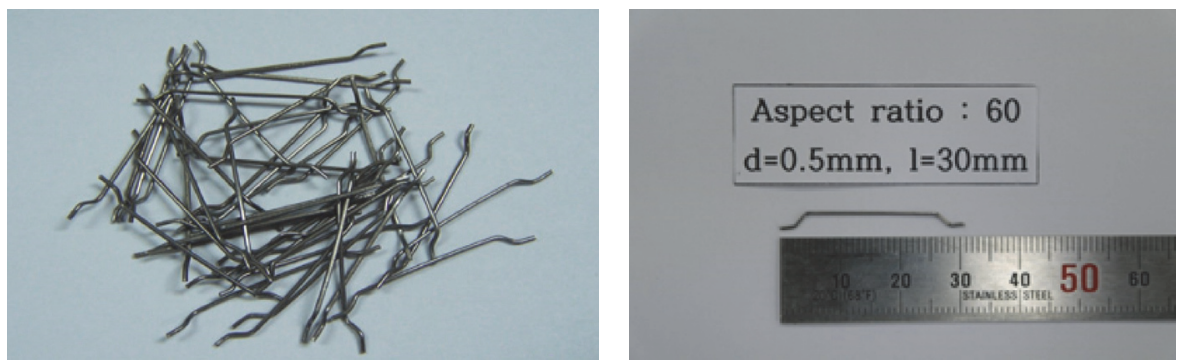

Figure 2: Type of steel fiber (hooked end).

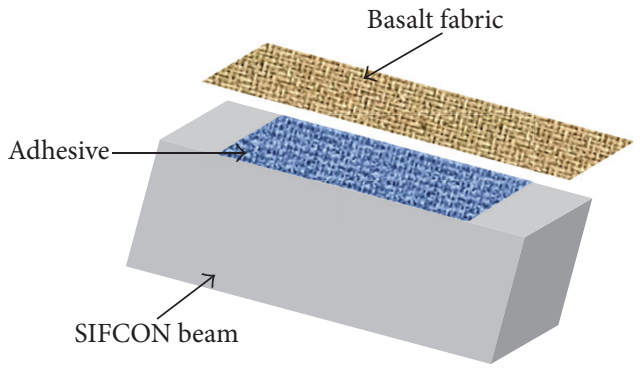

Figure 3: Single-layered basalt fabric applied over the HPFRCC beam with adhesive layer.

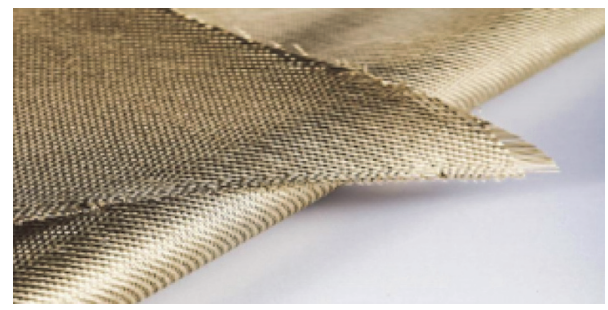

Figure 4: Basalt fiber sheet.

layer, adjacent to the adhesive-to-concrete interface, and adjacent to the FRP plate-to-adhesive interface [10-12]. The adhesive also acts as the matrix of the FRP, and this creates a strong bond with the beam. EFH 100S, EFR 100S, EFH 200S, and EFR 200S were used as adhesives in this experiment. Figure 3 shows the application of adhesive between the basalt sheet and HPFRCC beam.

2.1.6. Basalt Fiber-Reinforced Polymer Sheet. Figure 4 represents the basalt fiber sheet used in the study. Basalt (solidified volcanic lava) is known for its resistance to high temperatures, strength, and durability. BFRP is extruded from molten basalt rock at diameters generally between 13 and $20 \mu \mathrm{m}$. It is environmentally and ecologically harmless and is free from carcinogens and other health hazards. Compared with other fiber polymers, BFRP is similar to carbon fiber and fiberglass. However, it has better physic-mechanical properties than fiberglass and is comparatively cheaper than carbon fiber. It is used as a fireproof textile in the aerospace and automotive industries. Basalt fiber has a superior range of thermal performance $\left(-260^{\circ} \mathrm{C}\right.$ to $\left.960^{\circ} \mathrm{C}\right)$, and in addition, it has a
TABLE 2: Basalt fiber sheet properties.

\begin{tabular}{lc}
\hline Specific gravity & 2.6 \\
Tensile strength & $2,500 \mathrm{MPa}(360 \mathrm{ksi})$ \\
Elastic modulus & $89 \mathrm{GPa}(12,900 \mathrm{ksi})$ \\
Rupture strain & $3.15 \%$ \\
\hline
\end{tabular}

TABLE 3: Experimental variables in slurry mix matrix.

\begin{tabular}{lcc}
\hline Materials & Variables & Unit and remarks \\
\hline W/B ratio & 0.4 & - \\
Silica fume & 15 & $\begin{array}{c}\text { \%, binder weight } \\
\text { (cement replacement) }\end{array}$ \\
Fine aggregate content & 50 & $\%$, binder weight \\
Superplasticizer & 2.5 & $\%$, binder weight \\
Steel fiber & 8 & $\%$, volume ratio \\
\hline
\end{tabular}

high tensile strength, high resistance to alkalis and acids, and excellent electromagnetic properties. Furthermore, it is inert and has a high resistance to corrosion, radiation, UV light, and good resistance to vibration [13]. Some relevant mechanical properties of basalt fibers are summarized in Table 2.

2.2. Mixing Process. The ordinary Portland cement, fine aggregate, water, superplasticizer, and additional silica fume were mixed to prepare the slurry. The water content was fixed using a binder-to-water ratio of 0.4. Silica fume is typically used to increase the strength and durability in the more densely packed microstructure of the cement matrix. For a better performance of the slurry, the ordinary Portland cement was replaced with silica fume by $15 \%$ in cement weight. To improve the performance and resistance to segregation, the weight ratio of cement to fine aggregate was fixed at $0.5: 1$. Furthermore, $2.5 \%$ (of the cement weight) superplasticizer was added [14]. Table 3 summarizes the experimental variables for an optimum mix proportion of the slurry matrix.

First, molds for flexural strength specimens with dimensions of $100 \times 100 \times 400 \mathrm{~mm}$ were filled with steel fiber at a volume fraction of $8 \%$. The randomly sprinkled steel fibers should not overfill the depth of the mold, and the steel fibers should be leveled up as much as possible. The slurry, as prepared after mixing the contents, was poured from one end of the flexural beam in order to let it flow from one end to the other within the cluster of steel fiber. The slurry was poured 


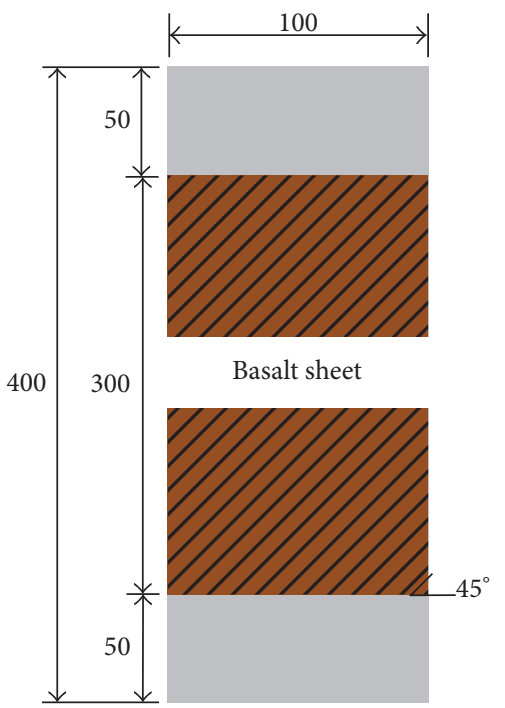

(a) BFRP orientation at $45^{\circ}$

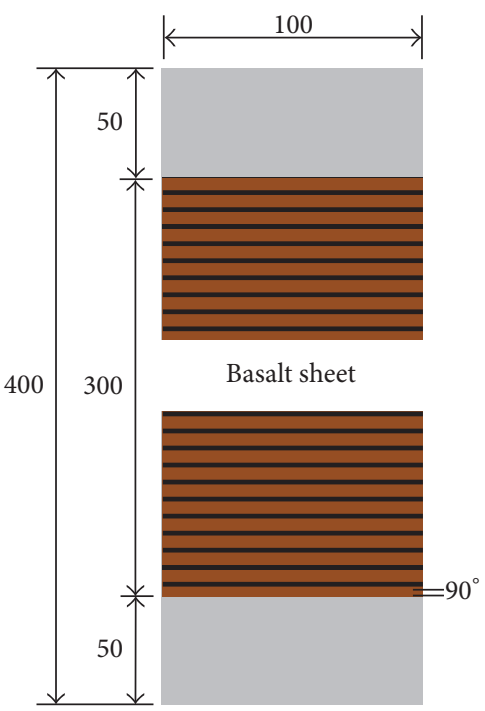

(b) BFRP orientation at $90^{\circ}$

FIgURE 5: Top view of orientation of FRP sheets to the axis of beam (tension zone).

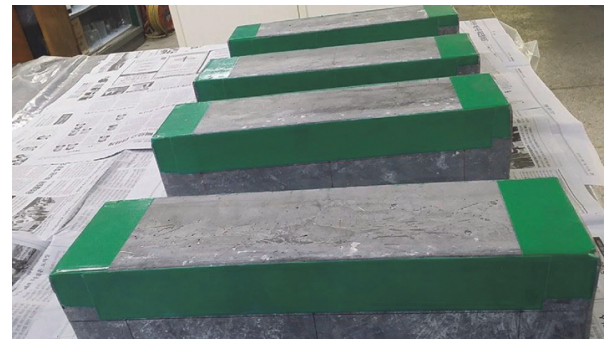

(a) HPFRCC beam for the application of BFRP

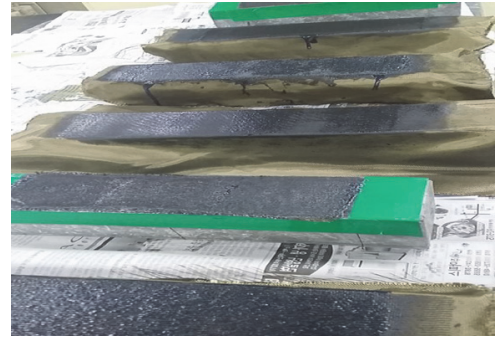

(b) Adhesive of BFRP to the HPFRCC beam

FIGURE 6: Ready-to-laminate and laminated beam with basalt sheet.

until bubbles were no longer observed to ensure infiltration of the slurry into the fibers as voids have a negative effect on the strength of concrete.

2.3. Concrete Specimen Preparation. After $24 \mathrm{~h}$, the specimens were demolded and transferred to a curing container. After curing the specimen for $28 \mathrm{~d}$ under a normal laboratory temperature of $23^{\circ} \mathrm{C}$, the specimens were taken out for the next process. A basalt fabric was cut with a dimension of $100 \mathrm{~mm} \times 300 \mathrm{~mm}$ with respect to the strip orientation of $45^{\circ}$ and $90^{\circ}$ angles. An adhesive was used to bind the beam surface with the fabric. We have prepared a total of nine variables from a single, double, and triple layer of basalt sheet laminated on the lower surface of the beam. Specimens were left for several days to ensure that the adhesive was perfectly set to bond the fabric with the beam surface, and then the next testing process was implemented. Here, Figure 5 shows the two different orientations of FRP sheets attached to the axis of beam in the tension zone and Figure 6 shows laboratory process of preparation and adhesion of BFRP sheet in the HPFRCC beam. Table 4 represents all the fiber orientation and combination that has been applied for research in this study.
2.4. Flexural Strength and Toughness Test. Figure 7 shows the four-point bending test performed in the laboratory and failure in the beams under the loading. The $100 \times 100 \times$ $400 \mathrm{~mm}$ flexural strength test specimens with $100 \times 300 \mathrm{~mm}$ basalt fabric bonded at the bending zone with different layers and fiber orientation were tested under a four-point bending test configuration following ASTM C1609, flexural testing of fiber-reinforced concrete beams. The method for conducting the test usually involves a specified test fixture on a universal testing machine (UTM). Specimens were loaded at four points by a 200-ton-class UTM, where the loaded power was applied by the displacement control at a speed of $1 \mathrm{~mm} / \mathrm{min}$ [15]. Details of the test preparation, conditioning, and procedure affect the test results. The vertical deflection was measured using Japanese yoke linear variable differential transformers on both sides simultaneously with the applied loading. A highly sensitive data logging instrument was used to collect the precise data for further analysis.

\section{Test Result Analysis and Discussion}

3.1. Flexural Strength and Toughness. The attachment of FRP sheet with adhesives is used to increase the flexural strength, 

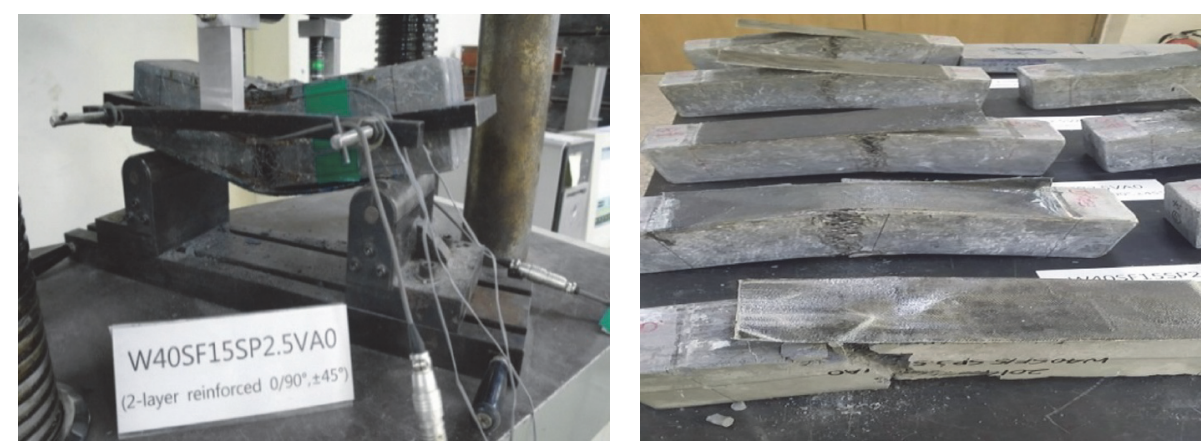

Figure 7: Load testing and failure under load.

TABLE 4: Variable specimens.

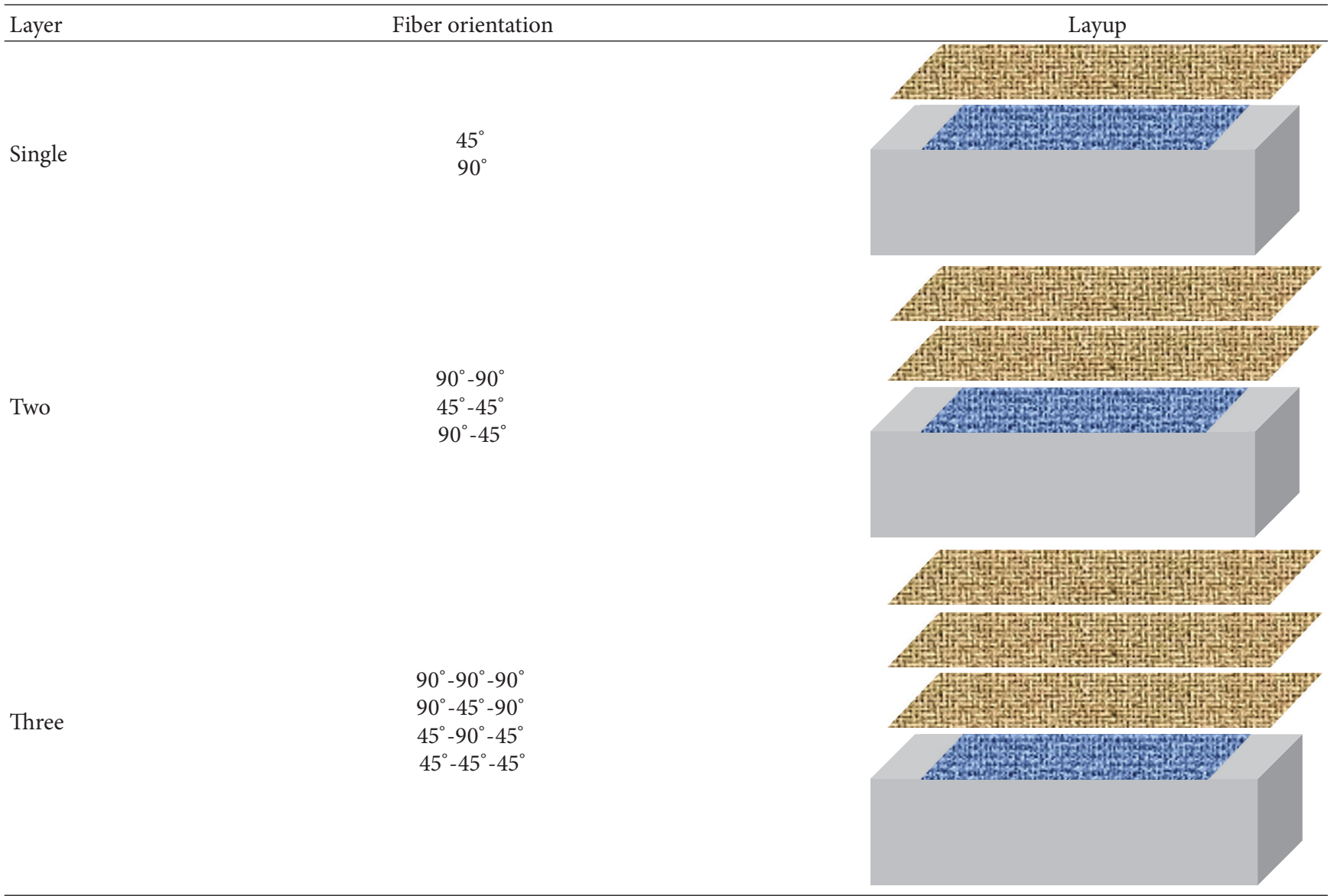

shear strength, and, to an extent, the flexural stiffness of the existing conventional slurry infiltrated fibrous concrete (SIFCON) beam. It is well known that the addition of the FRP external reinforcement decreases the deformity, that is, the deflection and curvature of failure of the member, and that the failure is brittle. Almost all the variable specimens showed a concrete failure. Compressive crushing of concrete was the dominant failure mode in all three layers of basalt retrofitted HPFRCC beams. The test results of flexural strength and the flexural toughness of the specimens are shown in Figures 8 and 9 , respectively.
Flexural toughness was calculated by using the loaddeflection graph of each variable. The limitation of ASTM C1609 was already considered, where the toughness was compared with the area under the curve up to a deflection of $15 \mathrm{~mm}$ (versus $L / 20$ ) [16].

3.1.1. HPFRCC Beam without BFRP. Figure 10 shows the load-mid span deflection curves of HPFRCC beams without BFRP. The result of the specimen without BFRP retrofit is the normal condition specimen. With respect to this result, the variable specimens with BFRP retrofit were compared. 


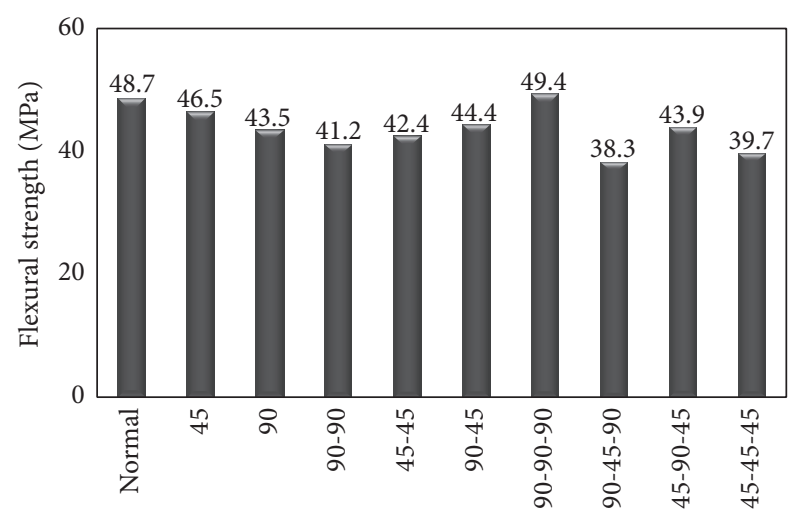

FIGURE 8: Flexural strength of the BFRP HPFRCC beam.

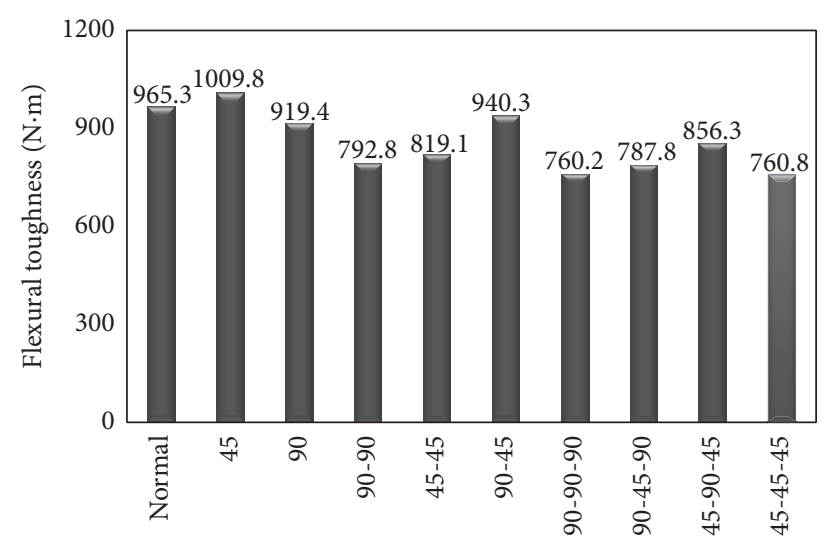

FIgURE 9: Flexural toughness of the BFRP HPFRCC beam.

Based on the research target, specimens retrofitted with layers of BFRP were expected to achieve better results. Here, the average flexural strength of the normal specimen was 48.7 $\mathrm{MPa}$, where the toughness calculated from the loaddeflection curve was $965.3 \mathrm{~N} \cdot \mathrm{m}$. The HPFRCC beam with a steel volume fraction of $8 \%$ is considered as a high strength concrete, and there are no differences in the strength and toughness.

3.1.2. Single-Layered BFRP HPFRCC Beam. Figure 11 shows the load-mid span deflection curves of single-layered BFRP HPFRCC beams. Beams with single-layered basalt polymer at different fiber angle orientations showed almost similar results. By examining the numerical values, the specimen with a $45^{\circ}$ fiber orientation, which has a toughness of $1009.8 \mathrm{~N} \cdot \mathrm{m}$, is observed to have the highest value compared with the others. The two single-layered specimens with different fiber orientations have better results compared with other specimens. Here, the specimen retrofitted with $45^{\circ}$ single-layer BFRP showed a higher value in comparison with the $90^{\circ}$. The optimum orientation of the FRP strips, as determined by Pantelides et al. (1999) [17], is $45^{\circ}$ owing to the cyclic nature of earthquakes. The fiber orientation at $45^{\circ}$ provided in both diagonal directions showed a better stiffness. The fiber orientation at $45^{\circ}$ provided in both diagonal direction orientations would limit the stiffness and

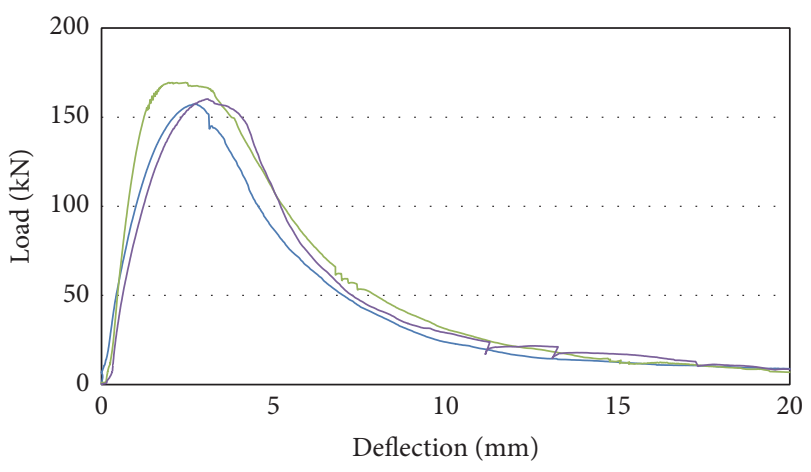

FIGURE 10: Load-mid span deflection curves of HPFRCC beam without BFRP.

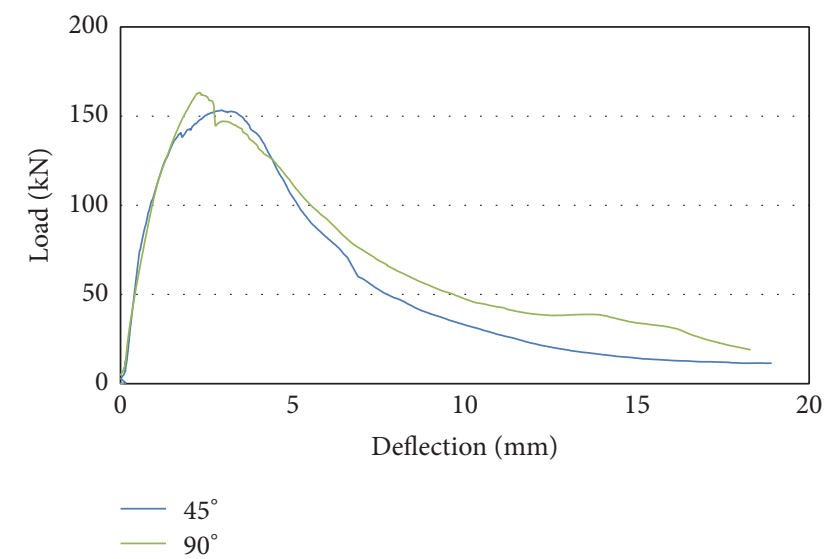

FIGURE 11: Load-mid span deflection curves of single-layered BFRP HPFRCC beam.

improve the shear capacity thus resulting in much more ductile behavior and increased toughness. The more ductile behavior exhibited by the specimen reinforced with $45^{\circ}$ oriented BFRP could probably be due to the enlargement of the failure zone associated with the stress redistribution.

3.1.3. Double-Layered BFRP HPFRCC Beam. Figure 12 shows the load-mid span deflection curves of double-layered BFRP HPFRCC beams. By close comparison, the specimen bonded with a $45^{\circ}$-oriented basalt fiber sheet showed better results in both cases. The flexural strength and toughness of the specimen bonded with different directions of basalt fiber sheets showed a comparatively better result (90-45). Here, the HPFRCC beam when retrofitted with $90^{\circ}$ - and $45^{\circ}$ oriented basalt fiber (i.e., specimen 90-45) showed a better toughness in comparison with that of the other specimens. This toughness of $940.3 \mathrm{~N} \cdot \mathrm{m}$ was one of the better specimens. This combination of layering basalt sheet can be a better option for an improved result. From the result, it was found that the specimen reinforced with $45^{\circ}$-oriented fiber specimen showed a better result than other layered combinations in the same category. Here, the increase in toughness and flexural strength is observed in the hybrid type of specimen (90-45) because the fiber orientation directly impacts the 


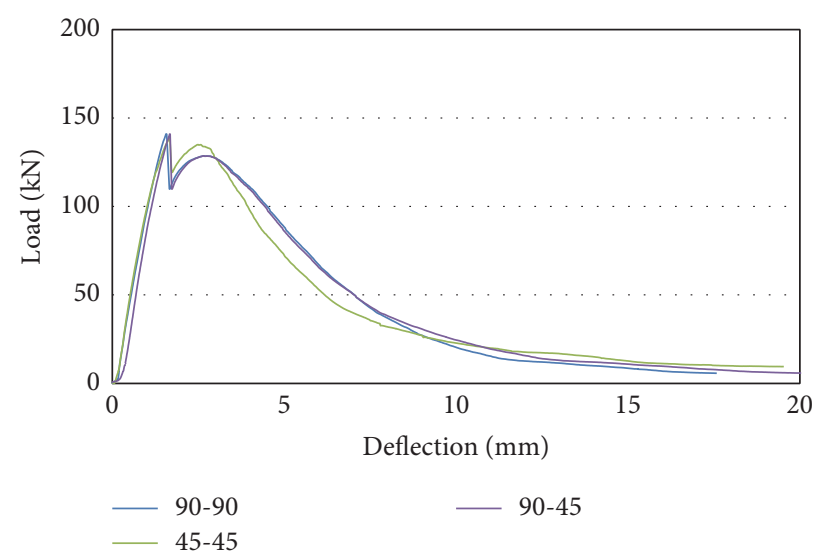

FIGURE 12: Load-mid span deflection curves of double-layered BFRP HPFRCC beam.

mechanical properties; therefore, it was logical to orient as many layers as possible to the main load-carrying direction. While this approach may work for some structures, it is usually necessary to use different directions with the hybrid type laminate. This type of combination of FRP layers carries an equal load in all four directions.

3.1.4. Three-Layered BFRP HPFRCC Beam. Figure 13 shows the load-mid span deflection curves of three-layered BFRP HPFRCC beams. Surprisingly, the three-layered beam specimens showed relatively different results. A remarkable difference was observed with the specimen, 90-90-90, which has the highest flexural strength and lowest toughness. Almost all the three-layered BFRP beam specimens showed similar flexural toughness except the variable, 45-90-45. Comparatively, the toughness was lower in value with that of the singleand double-layered specimens. This is an important issue to be considered-even a higher number of layers could result in lower toughness. Here, the specimen with $45^{\circ}$-oriented basalt fiber sheet when laminated in an alternative layer (4590-45) showed an increased toughness compared with the other three-layered basalt retrofitted variables. The irregular result could be due to the increase in strength, and stiffness is sometimes realized at the expense of a loss in ductility or the capacity of the structure to deflect in elastically while sustaining a load close to its capacity. The test result was similar with that of the double-layered BFRP specimen, when compared with the hybrid type of lamination. The specimen laminated in an alternative layer (45-90-45) had an increased toughness.

3.2. Discussion. A beam that failed by concrete crushing when a large quantity of FRP is used also shows a greatly reduced ductility (Buyukozturk and Hearing, 1998 [18]) [19]. The test results showed that the strength and toughness of the HPFRCC beam decreased with increasing number of BFRP layers. The forces in the FRP sheets/strips are directly proportional to the diagonal compressive stresses developed in the concrete struts. When these stresses exceed the concrete compressive strength, crushing of the concrete occurs. This failure is highly dependent on the crack angle and the FRP fiber orientation. The flatter the crack angle, the larger the

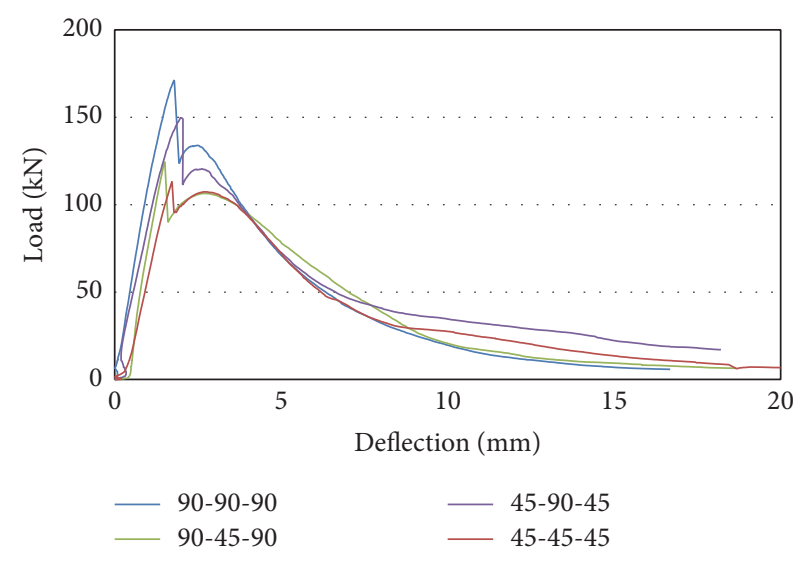

FIGURE 13: Load-mid span deflection curves of three-layered BFRP HPFRCC beam.

stresses developed. The FIB (Federation Internationale du Beton) Bulletin, FRP Reinforcement for Concrete Structure (2002) [20], noted that if the design is governed by the serviceability limit state, the quantity of FRP added into the structure may be considerably higher than what is required for the ultimate limit state.

In this case, it may be difficult to achieve the ductility requirement. Here, the SIFCON, which is already a highstrength concrete and was further reinforced externally by the BFRP, could be the reason behind the decrease in strength and toughness. Another reason could be that the failure mode of the specimen was in the concrete crushing of the beam, where the single-layered specimen showed a better flexural performance compared with the others. Therefore, the capacity is dependent on the strength of the concrete and shape of the specimens, and the failure is in the concrete rather than in the FRP-concrete interface.

Consequently, the strength decreased with the increased number of BFRP sheets. Although these are some of the result outputs worthy of discussion, the flexural performance and failure mode of the FRP concrete interface depend not only on the FRP sheet, fiber orientation, and layering but also on the stiffness, bond length, surface treatment, concrete strength, and adhesive layer stiffness, which are important factors that should be taken into consideration. Ductility index is used as the basis to evaluate the material behavior that represents the ability of a concrete beam to undergo a large deformation while maintaining its loadresisting capacity or a significant portion of it. It indicates the capability of the material to absorb and dissipate energy by postdeformation. Hence, the higher the ductility index, the better the performance.

\section{Conclusion}

This study is based on existing research work on HPFRCC beams strengthened by externally laminated BFRP in the tensile zone. Since the HPFRCC is already a high-strength concrete, the importance of this study was to further strengthen the HPFRCC by using a BFRP laminate. 
(1) Among the three different variable combinations, the single-layered $45^{\circ}$-oriented basalt fiber sheet reinforcement was the best method to strengthen the HPFRCC beam structure.

(2) From the test result, it was interesting to note that increasing the quantity of external reinforcement by increasing the BFRP thickness or layers does not always increase the maximum load ratio. Even the single-layered basalt retrofitted specimen showed better toughness in comparison with the other multilayered specimen. This means that more research is required on this field of improving the strength of HPFRCC retrofitted with multilayers of external basalt polymer.

(3) In the two-layer combination, different directions of basalt fiber sheet reinforcement showed higher toughness compared with other types. Moreover, the case was similar to the three-layer combination. The toughness improved when the $45^{\circ}$-oriented basalt fiber sheets were alternatively bonded with $90^{\circ}$ oriented basalt fiber sheets in two- and three-layered basalt reinforced beam (90-45 and 45-90-45).

(4) The decreasing strength value with the addition of FRP could be due to the reduced ductility. Strength and toughness are directly proportional to the ductility of the confinement, and we could relate this result with the overreinforcement, which reduces the ductility as well. The confinement with basalt fiber in hybrid orientation showed a better result because the load is distributed in all directions.

(5) Single-layered $45^{\circ}$-oriented basalt fibers limited the reinforcement and controlled the ductility as they provided stiffness in both diagonal directions. In conclusion, single-layered $45^{\circ}$-oriented basalt fiber sheet reinforcement is the most appropriate combination for strengthening an HPFRCC beam; in addition, it has a low installation time and is also economical.

\section{Competing Interests}

The authors declare that they have no competing interests.

\section{Acknowledgments}

This research was supported by a grant from a Construction Technology Research Project (development of impact/blast resistant HPFRCC and evaluation technique thereof, 13SCIPS02) funded by the Ministry of Land, Infrastructure, and Transport.

\section{References}

[1] L. Ostergaard, R. Walter, and J. F. Olesen, "Method for determination of tensile properties of engineered cementitious composites (ECC)," in Proceedings of the 3rd International Conference on Construction Materials, Performance, Innovations and Structural Implications, Vancouver, Canada, 2005.

[2] Country Reports on Terrorism 2010 [Internet]. State.gov, 2011, http://www.state.gov/j/ct/rls/crt/2010/.
[3] J. Zhang and H. Stang, "Applications of stress crack width relationship in predicting the flexural behavior of fibre-reinforced concrete," Cement and Concrete Research, vol. 28, no. 3, pp. 439452, 1998.

[4] A. Naaman, "High performance fibre reinforced cement composites," in High Performance Construction Materials, C. Shi and Y. Mo, Eds., Science and Applications, pp. 91-154, 1st edition, 2008.

[5] A. Naaman and H. Reinhardt, "High performance fiber reinforced cement composites HPFRCC-4: international workshop Ann Arbor, Michigan, June 16-18, 2003," Cement and Concrete Composites, vol. 26, no. 6, pp. 757-759, 2004.

[6] P. Balaguru, A. Nanni, and J. Giancaspro, FRP Composites for Reinforced and Prestressed Concrete Structures, Taylor \& Francis, New York, NY, USA, 2009.

[7] H. GangaRao, N. Taly, and P. Vijay, Reinforced Concrete Design with FRP Composites, CRC Press, Boca Raton, Fla, USA, 2007.

[8] H. He and W. Dong, "Study on damaged reinforced concrete beams strengthened with basalt fiber polymer sheets," Advanced Materials Research, vol. 446-449, pp. 2941-2944, 2012.

[9] R. Siddique and M. Khan, Supplementary Cementing Materials, Springer, Heidelberg, Germany, 2011.

[10] U. Meier, "Strengthening of structures using carbon fibre/epoxy composites," Construction and Building Materials, vol. 9, no. 6, pp. 341-351, 1995.

[11] V. M. Karbhari and L. Zhao, "Issues related to composite plating and environmental exposure effects on composite-concrete interface in external strengthening," Composite Structures, vol. 40, no. 3-4, pp. 293-304, 1997.

[12] Leeming and Darby, Design and Specifications for FRP Plate Bonding of Beams: Chapter 9 of Strengthening of Reinforced Concrete Structures Using Externally-Bonded FRP Composites, Woodhead, Cambridge, UK, 1999.

[13] J. Sim, C. Park, and D. Y. Moon, "Characteristics of basalt fiber as a strengthening material for concrete structures," Composites Part B: Engineering, vol. 36, no. 6-7, pp. 504-512, 2005.

[14] S. Kim, C. Park, S. Kim, H. Cho, S. Jeon, and M. Ju, "Optimum mix proportions of in-fill slurry for high performance steel fiber reinforced cementitious composite," Journal of the Korean Recycled Construction Resources Institute, vol. 2, no. 3, pp. 196201, 2014.

[15] S. Kim, H. Cho, H. Lee, and C. Park, "Flexural performance characteristics of high performance slurry infiltrated fiber reinforced cementitious composite according to fiber volume fraction," Journal of the Korea Institute for Structural Maintenance and Inspection, vol. 19, no. 4, pp. 109-115, 2015.

[16] S. Kim, H. Ban, M. Ju, H. Cho, and C. Park, "Performance fiber reinforced cementitious composites under mode I fracture," in Proceedings of the 5th International Conference on Design and Analysis of Protective Structures (DASP '15), pp. 975-981, Singapore, 2015.

[17] C. P. Pantelides, J. Gergely, L. D. Reaveley, and V. A. Volnyy, "Retrofit of RC bridge pier with CFRP advanced composites," Journal of Structural Engineering. ASCE, vol. 9, no. 4, pp. 10941099, 1999.

[18] O. Buyukozturk and B. Hearing, "Failure behavior of precracked concrete beams retrofitted with FRP," Journal of Composites for Construction, vol. 2, no. 3, pp. 138-144, 1998.

[19] S. Kim and C. Park, "Mechanical properties of high performance fiber reinforced composite with high steel fiber volume fraction," in Fibre Concrete 2015, Checz Technical University in Prague, Prague, Czech Republic, 2015. 
[20] "Recommendations of RILEM TC 162-TDF: test and design methods for steel fibre reinforced concrete: bending test," Materials and Structures, vol. 35, no. 253, pp. 579-582, 2002. 


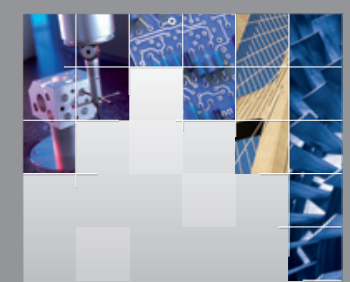

\section{Enfincering}
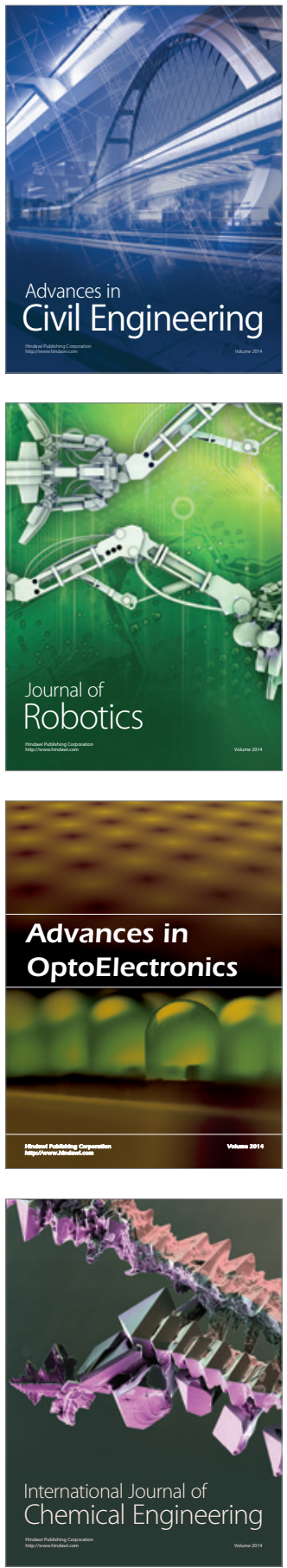

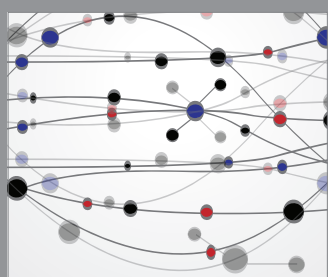

The Scientific World Journal

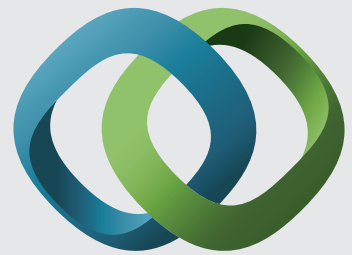

\section{Hindawi}

Submit your manuscripts at

http://www.hindawi.com
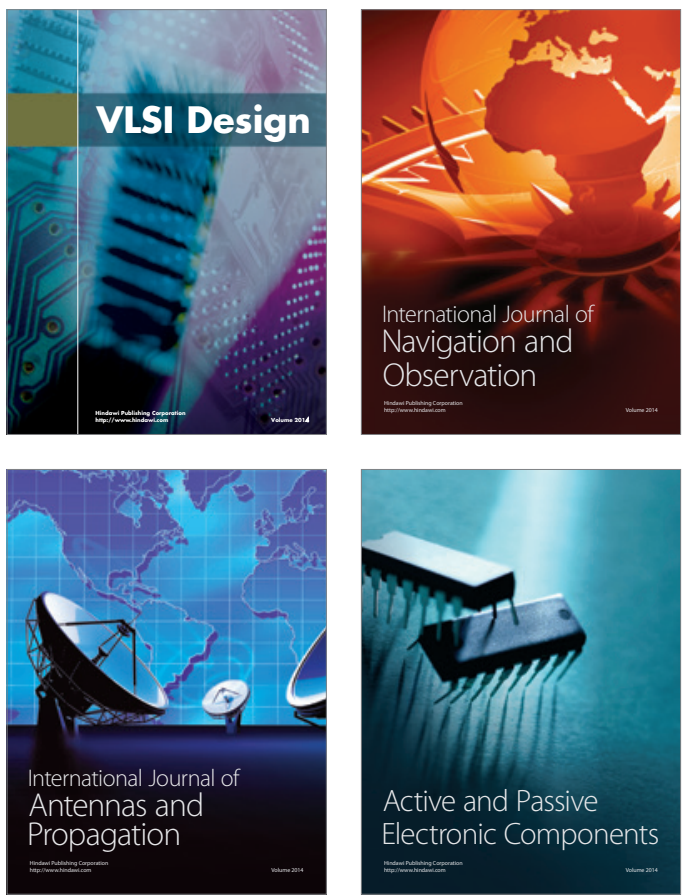
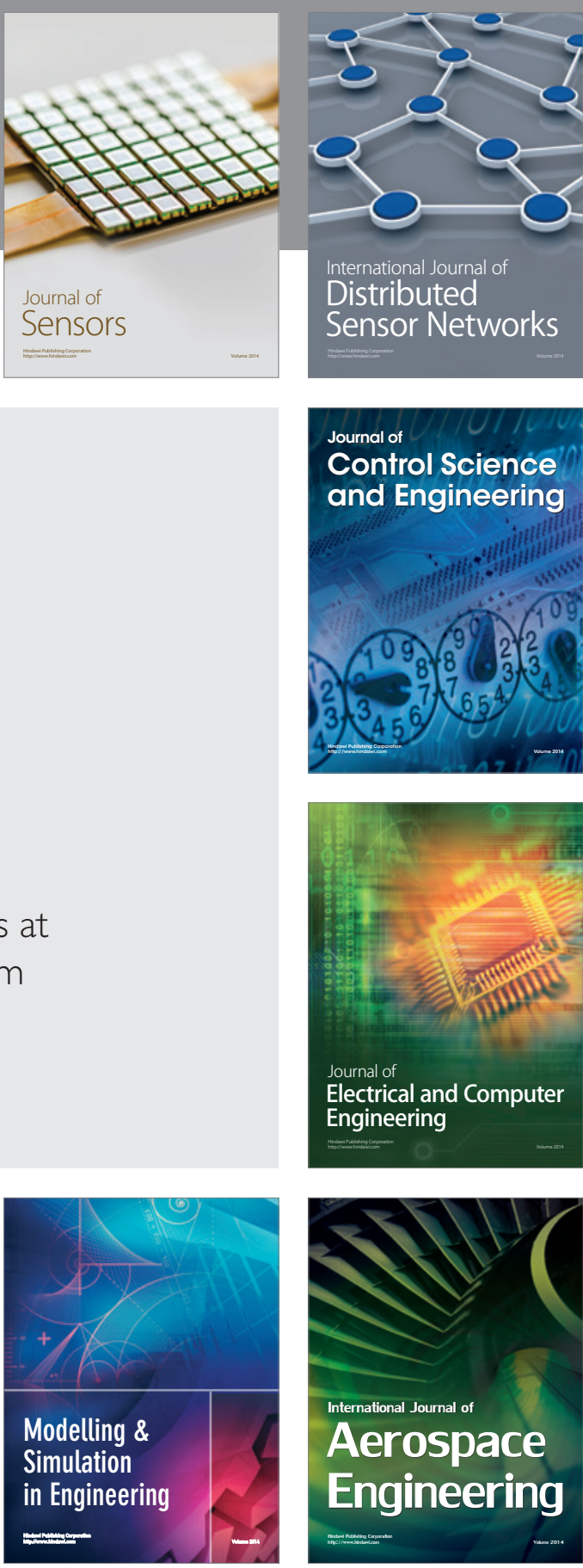

International Journal of

Distributed

Sensor Networks

Journal of

Control Science

and Engineering
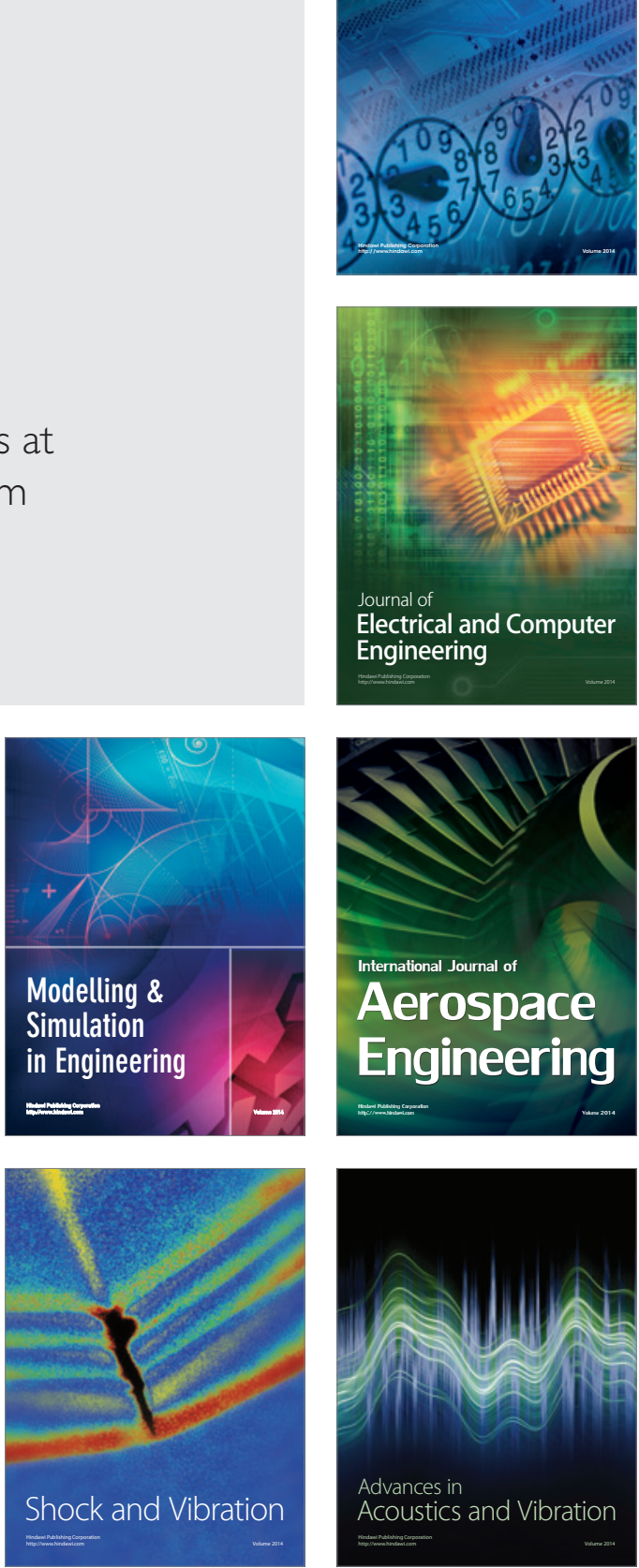